\title{
Efeito da casca de banana na dieta de vacas em lactação sobre as características do leite e do queijo Minas frescal*
}

\section{Effect of banana peel in the diet of lactating cows on the characteristics of milk and cheese Minas frescal}

\author{
Cláudia Ribeiro Antunes, ${ }^{* *}$ Vicente Ribeiro Rocha Júnior, ${ }^{* * *}$ Luciana Albuquerque Caldeira, ${ }^{* * *}$ Criszoel Ferreira Souza, ${ }^{* *}$ \\ João Paulo Sampaio Rigueira, ${ }^{* * *}$ Guilherme Reis de Souza, ${ }^{* * *}$ Wagner Sousa Alves, ${ }^{* * * *}$ Camila Soares, ${ }^{* *}$ \\ Jordana Carvalho de Menezes**
}

\begin{abstract}
Resumo
Objetivou-se avaliar qualidade do leite e do queijo Minas frescal produzido do leite de vacas alimentadas com inclusão da casca de banana seca ao sol, com ou sem adição de agentes químicos durante o processo de secagem. Foram utilizadas oito vacas $\mathrm{F} 1$ Holandês $\times$ Zebu, em dois quadrados latinos $4 \times 4$, com as seguintes dietas experimentais: dieta convencional com silagem de sorgo sem a inclusão da casca de banana (controle); dieta com inclusão da casca de banana seca ao sol em substituição de $20 \%$ da silagem de sorgo; dieta com inclusão da casca de banana seca ao sol com $2 \%$ de calcário em substituição de $20 \%$ da silagem de sorgo; dieta com inclusão da casca de banana seca ao sol com $2 \%$ de óxido de cálcio em substituição de $20 \%$ da silagem de sorgo. As amostras de leite de cada vaca foram coletadas e analisadas quanto aos teores de gordura, proteína, lactose, cinzas, sólidos totais e extrato seco desengordurado. Após esta etapa, foi realizada a elaboração de queijo Minas frescal, sendo verificados rendimento, textura, acidez titulável, $\mathrm{pH}$, proteína, teor de umidade, gordura, resíduo mineral fixo, extrato seco total e realizado o teste de aceitação pelo consumidor. A composição química do leite e do queijo não apresentou influência das dietas com casca de banana. Entretanto, o rendimento ajustado para produção de queijo foi estatisticamente inferior com as dietas contendo casca de banana tratada com os aditivos químicos. Quanto à aceitação geral dos queijos pelos consumidores, não houve diferenças entre os tratamentos. Desse modo, a utilização de casca de banana seca ao sol sem aditivos químicos em substituição parcial à silagem de sorgo na dieta de vacas em lactação pode ser uma alternativa viável para produção e processamento do leite, mantendo a qualidade do produto.
\end{abstract}

Palavras-Chave: bananicultura, dieta, leite, qualidade, queijo

\begin{abstract}
It aimed to evaluate the quality of milk and cheese from cows fed inclusion of banana peel dried under the sun, with or without chemical additives during the drying process. We used eight F1 Holstein $\times$ Zebu cows in two latin squares $4 \times 4$ with the following experimental diets: conventional diet with sorghum silage without the inclusion of banana peel (control); diet with the inclusion of dry banana peel in the sun replacing $20 \%$ of sorghum silage; diet with the inclusion of dry banana peel in the sun with $2 \%$ limestone replacing $20 \%$ of sorghum silage; diet with the inclusion of dry banana peel in the sun with $2 \%$ calcium oxide replacing $20 \%$ of sorghum silage. The milk samples from each cow were collected and analyzed for fat, protein, lactose, ashes, total solids and dry fat extract. After this stage, Minas frescal cheese was elaborated, yield, texture, titratable acidity, $\mathrm{pH}$, protein, moisture content, fat, fixed mineral residue, total dry extract and the consumer acceptance test were performed. The chemical composition of milk and cheese showed no effect of diets with the banana peel inclusion. However, the yield adjusted for cheese production was statistically lower with diets containing banana peel treated with chemical additives. As for general acceptance of the cheeses by consumers, there were not differences between treatments. Thus, the use of banana skin dried under the sun without chemical additives for partial replacement of sorghum silage in diet of lactating cows may be a viable alternative to milk production and processing, maintaining the quality.
\end{abstract}

Keywords: banana culture, diet, milk, quality, cheese

*Recebido em 6 de setembro de 2015 e aceito em 14 de março de 2018.

** Mestres em Zootecnia pelo Programa de Pós-Graduação em Zootecnia da Unimontes, Campus de Janaúba/MG, Brasil;

***Professores do Departamento de Ciências Agrárias da Unimontes, Campus de Janaúba/MG, Brasil; Bolsistas de Produtividade em Pesquisa da FAPEMIG; Autor para correspondência: vicente,rocha@unimontes.br;

****Mestrando em Zootecnia pelo Programa de Pós-Graduação em Zootecnia da Unimontes, Campus de Janaúba/MG, Brasil;

*****Mestrando em Zootecnia pelo Programa de Pós-Graduação em Zootecnia da UFV, Viçosa/MG, Brasil; 


\section{Introdução}

A alimentação da vaca pode influenciar o valor nutritivo do leite e dos derivados lácteos (Oliveira et al., 2007; Aguiar et al., 2013; Nudda et al., 2014). Além disso, alimentos saudáveis são cada vez mais procurados pelos consumidores (Fernandes et al., 2008). Associado a isso, os custos com alimentação dos animais representam um dos fatores que mais onera o custo de produção (Bosa et al., 2012). Com isso, o aproveitamento de subprodutos ou resíduos das agroindústrias tem recebido atenção especial (Omer, 2009).

Entretanto, a elevada umidade dos subprodutos agroindustriais prejudica a sua utilização, pois há a proliferação de microrganismos que deterioram o produto, além de onerar os custos com o transporte. Diante disso, a utilização de aditivos químicos alcalinizantes, como o óxido de cálcio e o calcário, ajuda a desidratação desses produtos e possuem também a função de melhorar o valor nutritivo dos mesmos (Carvalho et al., 2006).

A utilização dos subprodutos/resíduos da bananicultura como matéria-prima, além dos benefícios econômicos, representaria a redução de impactos ambientais, visto que são descartados no ambiente e promovem custos adicionais às empresas processadoras (Lousada júnior et al., 2005). Pimentel et al. (2017), ao substituírem a silagem de sorgo em até $60 \%$ pela casca de banana seca ao sol, não verificaram diferenças na produção de leite e na produção corrigida para 3,5\% de gordura, que apresentou média de 16,49 kg/dia.

A casca da banana possui um notório valor nutricional, constituindo uma rica fonte de carboidratos, principalmente a pectina (10 a $21 \%$ ), carboidrato altamente fermentável no rúmen (Mahopatra et al., 2010). Em sua composição, os lipídeos apresentam bom perfil de ácidos graxos, com teor de extrato etéreo variando de 2 a 10,9\% (Mohapatra et al., 2010), constituído principalmente de ácido linoléico e $\alpha$-linolênico, responsáveis por aumentar o níveis de HDL no sangue, prevenindo doenças cardiovasculares (Demeyer e Doreau, 1999). É fonte de galocatequina, composto flavonóide, que possui ação anti-inflamatória, antimicrobiana e antioxidante (Havsteen, 2002), o que pode ajudar na saúde da glândula mamária da vaca em lactação. Apresenta ainda taninos em sua composição, os quais interferem de maneira positiva na biohidrogenação ruminal do ácido linoléico dietético, aumentando a concentração de ácido vacênico no rúmen e, portanto, o conteúdo de ácido linoléico conjugado (CLA) (Toral et al., 2011).

Objetivou-se com este trabalho avaliar os efeitos da inclusão da casca de banana seca ao sol com ou sem adição de agentes químicos durante o processo de secagem na dieta de vacas F1 Holandês x Zebu sobre a qualidade do leite e do queijo Minas frescal.

\section{Material e métodos}

O experimento foi conduzido na Fazenda Experimental da Universidade Estadual de Montes Claros - UNIMONTES, localizada no Município de Janaúba/MG. As análises foram realizadas nos Laboratórios de Análise de Alimentos e de Tecnologia de Produtos de Origem Animal da UNIMONTES Campus Janaúba.
Foram utilizadas oito vacas F1 Holandês x Zebu, com $80 \pm$ 10 dias de lactação ao início do experimento. O delineamento experimental adotado foram dois quadrados latino $4 \times 4$, composto, cada um, de quatro animais, quatro tratamentos e quatro períodos experimentais. A casca de banana foi adquirida em uma indústria de doces da região e era da variedade "Prata". Foram utilizadas quatro dietas experimentais, conforme tabela 1. A substituição da silagem de sorgo pela casca de banana foi feita com base na matéria seca.

O experimento teve duração de 72 dias, dividido em quatro períodos de 18 dias, sendo que os primeiros 14 dias de cada período foram reservados para adaptação dos animais às dietas e os quatro últimos dias para coleta de dados e amostras.

As dietas foram formuladas para serem isonitrogenadas, para vacas com média de $450 \mathrm{~kg}$ de peso vivo e produção média de $15 \mathrm{~kg}$ de leite corrigido para 3,5\% de gordura $\mathrm{dia}^{-1}$, conforme o National Research Council (NRC, 2001) e foram fornecidas para as vacas duas vezes ao dia, às $07 \mathrm{~h}$ e às $14 \mathrm{~h}$.

$\mathrm{O}$ volumoso foi pesado diariamente em balança digital, distribuído nos cochos e misturado com os concentrados e o percentual de casca de banana de cada tratamento. As sobras do cocho foram pesadas e registradas diariamente. $O$ fornecimento das dietas foi ajustado de acordo com as sobras, mantendo a relação volumoso:concentrado com base na matéria seca (MS) de $75: 25$, de forma que as sobras representassem $10 \%$ da quantidade fornecida. A proporção dos ingredientes utilizados nas dietas e a composição química das mesmas encontram-se na Tabela 1 e a composição dos ingredientes na Tabela 2.

Os animais foram ordenhados por ordenha mecânica, com bezerro ao pé, duas vezes ao dia, às $08 \mathrm{~h}$ e às $15 \mathrm{~h}$. As amostras de leite de cada animal foram coletadas duas vezes ao dia, nos últimos quatro dias de cada período, sendo feito um pool das amostras do leite da ordenha da manhã e da tarde, proporcionalmente à quantidade produzida de manhã e à tarde. Após a ordenha de cada vaca, o leite foi homogeneizado, e coletada uma amostra de $500 \mathrm{~mL}$. Posteriormente, essas amostras foram encaminhadas ao Laboratório de Tecnologia de Produtos de Origem Animal da Unimontes - Campus de Janaúba e no mesmo dia foram realizadas as análises físico-químicas. As produções de leite corrigidas para 3,5\% de gordura foram calculadas utilizando-se a equação proposta por Sklan et al. (1994).

Para determinação das características químicas do leite, foram realizadas as seguintes análises, em triplicata: acidez titulável $\left({ }^{\circ} \mathrm{D}\right)$, densidade a $15{ }^{\circ} \mathrm{C}$ e índice crioscópico $\left({ }^{\circ} \mathrm{H}\right)$, de acordo com Brasil (2006); teor de gordura, proteína, cinzas e lactose por aparelho eletrônico Milk Analizer Master Classic LMZ. O cálculo do extrato seco total (EST) foi obtido por meio de leitura no aparelho eletrônico, e o extrato seco desengordurado (ESD) pela subtração do teor de gordura (Brasil, 2006).

O queijo Minas frescal foi fabricado no Laboratório de Tecnologia de Produtos de Origem Animal da UNIMONTES - Campus Janaúba, de acordo com a técnica recomendada por Furtado e Lourenço Neto (1994). O leite de cada dieta experimental, separadamente, foi pesado, filtrado e submetido à pasteurização lenta $\left(65^{\circ} \mathrm{C}\right.$ por 30 minutos). Após esse tratamento térmico, o leite foi resfriado a $39^{\circ} \mathrm{C}$, temperatura em que foram adicionados o cloreto de cálcio $(40 \mathrm{~mL} / 100 \mathrm{~L})$ e o coalho (30 
Tabela 1: Proporção dos ingredientes das dietas experimentais (\%) e composição química das dietas, na base da matéria seca (\%)

\begin{tabular}{|c|c|c|c|c|}
\hline \multirow[t]{2}{*}{ Ingredientes } & \multicolumn{4}{|c|}{ Dietas Experimentais (\% MS) } \\
\hline & $\begin{array}{l}\text { Silagem } \\
\text { de sorgo }\end{array}$ & $\begin{array}{c}\text { Silagem + Casca } \\
\text { Banana }\end{array}$ & $\begin{array}{l}\text { Silagem + Casca } \\
\text { Banana c/ calcário* }\end{array}$ & $\begin{array}{c}\text { Silagem +Casca } \\
\text { Banana c/ cal virgem* }\end{array}$ \\
\hline Silagem de sorgo & 75,00 & 55,00 & 55,00 & 55,00 \\
\hline Farelo de soja & 9,94 & 9,94 & 8,53 & 8,53 \\
\hline Milho moído & 14,06 & 14,06 & 15,47 & 15,47 \\
\hline Casca de banana & 0,00 & 20,00 & 0,00 & 0,00 \\
\hline Casca de banana com calcário & 0,00 & 0,00 & 20,00 & 0,00 \\
\hline Casca de banana com cal virgem & 0,00 & 0,00 & 0,00 & 20,00 \\
\hline \multirow[t]{2}{*}{ Suplemento mineral } & 1,00 & 1,00 & 1,00 & 1,00 \\
\hline & \multicolumn{4}{|c|}{ Composição Química (\% da MS) } \\
\hline Matéria Seca (\%) & 30,43 & 30,78 & 31,79 & 30,92 \\
\hline Matéria Orgânica (\%) & 94,98 & 92,74 & 91,52 & 91,41 \\
\hline Proteína Bruta (\%) & 11,33 & 11,42 & 10,90 & 10,89 \\
\hline${ }^{1} \mathrm{NIDN}(\%)$ & 0,58 & 0,52 & 0,53 & 0,52 \\
\hline${ }^{2} \mathrm{NIDA}(\%)$ & 0,025 & 0,024 & 0,025 & 0,025 \\
\hline Extrato Etéreo (\%) & 2,42 & 3,77 & 3,33 & 3,62 \\
\hline Carboidratos Totais (\%) & 77,35 & 74,44 & 74,52 & 74,17 \\
\hline Carboidratos não fibrosos (\%) & 17,48 & 16,97 & 17,50 & 17,76 \\
\hline Fibra em detergente neutro (\%) & 59,86 & 57,48 & 57,71 & 56,40 \\
\hline${ }^{3} \mathrm{FDNcp}(\%)$ & 54,15 & 52,23 & 52,32 & 52,31 \\
\hline Fibra em detergente ácido (\%) & 31,00 & 31,83 & 30,47 & 29,58 \\
\hline Lignina & 8,11 & 10,21 & 10,90 & 10,59 \\
\hline${ }^{4}$ Nutrientes Digestíveis Totais & 63,15 & 64,16 & 64,43 & 64,02 \\
\hline
\end{tabular}

" $2 \%$ de calcário e $2 \%$ de cal virgem;

${ }^{1} \mathrm{NIDN}=$ nitrogênio insolúvel em detergente neutro; ${ }^{2} \mathrm{NIDA}=$ nitrogênio insolúvel em detergente ácido; ${ }^{3} \mathrm{FDNcP}=$ Fibra em detergente neutro corrigida para cinza e proteína. ${ }^{4}$ Estimado pelas equações do NRC (2001)

Tabela 2: Composição química dos ingredientes das dietas experimentais, com base na matéria seca

\begin{tabular}{|c|c|c|c|c|c|c|}
\hline \multicolumn{7}{|c|}{ Composição Química } \\
\hline$(\%)$ & $\begin{array}{l}\text { Silagem de } \\
\text { Sorgo }\end{array}$ & $\begin{array}{c}\text { Casca de } \\
\text { Banana }\end{array}$ & $\begin{array}{c}\text { Casca de Banana + } \\
2 \% \text { Calcário }\end{array}$ & $\begin{array}{l}\text { Casca de Banana + } \\
2 \% \text { óxido de Cálcio }\end{array}$ & $\begin{array}{l}\text { Milho grão } \\
\text { moído }\end{array}$ & $\begin{array}{l}\text { Farelo de } \\
\text { Soja }\end{array}$ \\
\hline Matéria Seca & 31,62 & 91,68 & 92,43 & 92,69 & 91,09 & 91,45 \\
\hline Matéria Orgânica & 92,69 & 86,01 & 81,13 & 80,72 & 98,64 & 93,59 \\
\hline Proteína Bruta & 8,12 & 8,82 & 8,74 & 8,67 & 8,60 & 49,28 \\
\hline${ }^{1} \mathrm{NIDN}$ & 4,38 & 10,65 & 10,48 & 11,23 & 4,82 & 12,27 \\
\hline${ }^{2} \mathrm{NIDA}$ & 4,03 & 9,80 & 9,66 & 10,34 & 4,44 & 11,31 \\
\hline Extrato Etéreo & 1,74 & 8,46 & 6,37 & 7,81 & 4,18 & 5,34 \\
\hline Carboidratos Totais & 82,83 & 68,73 & 66,02 & 64,24 & 85,86 & 38,83 \\
\hline${ }^{3} \mathrm{CNF}$ & 15,01 & 12,83 & 11,89 & 14,08 & 48,70 & 11,73 \\
\hline${ }^{4} \mathrm{FDN}$ & 69,24 & 57,32 & 57,78 & 51,25 & 37,16 & 27,24 \\
\hline${ }^{5}$ FDNcp & 67,82 & 55,90 & 54,13 & 50,16 & 36,17 & 26,30 \\
\hline${ }^{6} \mathrm{FDA}$ & 37,66 & 41,81 & 40,30 & 35,88 & 4,67 & 11,45 \\
\hline Lignina & 10,11 & 20,61 & 23,94 & 22,40 & 2,87 & 1,27 \\
\hline${ }^{7} \mathrm{NDT}$ & 49,4 & 45,80 & 46,28 & 46,89 & 83,50 & 80,22 \\
\hline
\end{tabular}

${ }^{1} \mathrm{NIDN}=$ nitrogênio insolúvel em detergente neutro; ${ }^{2} \mathrm{NIDA}=$ nitrogênio insolúvel em detergente ácido; ${ }^{3} \mathrm{CNF}=$ carboidratos totais; ${ }^{4} \mathrm{FDN}=\mathrm{Fibra}$ em detergente neutro; ${ }^{5} \mathrm{FDNCP}=$ Fibra em detergente neutro corrigida para cinza e proteína; ${ }^{6} \mathrm{FDA}=$ fibra em detergente ácido; ${ }^{7} \mathrm{NDT}=$ nutrientes digestíveis. 
$\mathrm{mL} / 100 \mathrm{~L})$, sendo este diluído em parte igual com água filtrada. Após um tempo de 40 a 60 minutos, ocorreu a coagulação do leite, em seguida foi realizado o corte da massa com uma faca inox em cubos de 1,5 a $2 \mathrm{~cm}$, intercalando a mexedura e o repouso para promover a dessoragem. Seguida a drenagem do soro, a massa foi colocada em formas plásticas e procedeu-se à salga $(700 \mathrm{~g} / 100 \mathrm{~L}$ de sal branco refinado). Os queijos foram resfriados numa temperatura de $4{ }^{\circ} \mathrm{C}$ por aproximadamente 12 horas, no dia seguinte foram retirados das formas, embalados, pesados em balança digital para determinação do rendimento e reservados para posteriores análises de textura, físicoquímica e sensorial.

A textura das amostras de queijo foi determinada utilizando-se um Texturômetro - Modelo TAXT da Stabic Micro Systems, com auxílio de um Software, fornecendo diretamente a força de corte $(\mathrm{Kg})$. Foi utilizada uma célula do tipo Probe Warner Bratzler. O rendimento bruto dos queijos foi calculado segundo a equação de Andreatta et al.

Tabela 3: Composição físico-química e produção de leite de vacas alimentadas com ou sem inclusão de casca de banana na dieta, com respectivas médias e coeficientes de variação $(\mathrm{CV})$

\begin{tabular}{lcccccc}
\hline \multirow{2}{*}{ Variáveis } & \multicolumn{7}{c}{ Dietas Experimentais } \\
\cline { 2 - 7 } & $\mathrm{SS}^{4}$ & $\mathrm{SS}^{4}+$ Casca & $\begin{array}{c}\mathrm{SS}^{4}+\text { Casca } \\
\text { c/ calcário }\end{array}$ & $\begin{array}{c}\mathrm{SS}^{4}+\text { Casca cl } \\
\text { óxido de Cálcio }\end{array}$ & Média geral & CV(\%) \\
\hline Gordura (\%) & 4,72 & 4,64 & 4,75 & 4,57 & 4,67 & 7,39 \\
Gordura (g/dia) & 668,38 & 634,22 & 692,45 & 645,66 & 660,17 & 13,89 \\
Proteína (\%) & 3,74 & 3,75 & 3,76 & 3,67 & 3,73 & 5,09 \\
Proteína (g/dia) & 529,78 & 512,03 & 546,84 & 521,54 & 527,50 & 12,88 \\
Lactose (\%) & 4,95 & 4,99 & 5,01 & 4,90 & 4,96 & 3,87 \\
Cinzas (\%) & 0,79 & 0,79 & 0,79 & 0,78 & 0,79 & 3,58 \\
${ }^{1}$ ST (\%) & 14,12 & 14,10 & 14,26 & 13,86 & 14,08 & 4,70 \\
${ }^{2}$ ESD (\% ) & 9,41 & 9,46 & 9,51 & 9,30 & 9,42 & 3,71 \\
Densidade (g/mL) & 1,030 & 1,031 & 1,031 & 1,030 & 1,031 & 0,16 \\
Crioscopia (m $\left.{ }^{\circ} \mathrm{H}\right)$ & $-0,530$ & $-0,531$ & $-0,533$ & $-0,531$ & $-0,532$ & 0,73 \\
${ }^{3}$ PLCG (Kg) & 17,00 & 16,25 & 17,50 & 16,63 & 16,84 & 14,18 \\
\hline
\end{tabular}

${ }^{1}$ Teor de Sólidos Totais, ${ }^{2}$ Teor de Extrato Seco Desengordurado, ${ }^{3}$ Produção de leite corrigida para 3,5\% gordura, ${ }^{4}$ Silagem de Sorgo.

(2009). O rendimento ajustado para o teor de umidade do queijo (Lucey e Kelly, 1994) foi calculado considerando um valor de $57 \%$ como referência para a umidade do queijo minas frescal, conforme a equação sugerida por Furtado (2005).

Para determinação das características químicas do queijo, foram realizadas as seguintes análises, em triplicata: acidez titulável ( $\left.{ }^{\circ} \mathrm{D}\right), \mathrm{pH}$, teores de gordura, proteína, resíduo mineral fixo, sólidos totais e umidade, conforme Brasil (2006). A atividade de água (Aw) foi avaliada por meio de medidor de Aw modelo Aqua Lab.

A análise sensorial foi realizada no Laboratório de Tecnologia de Produtos de Origem Animal da UNIMONTES - Campus Janaúba. A avaliação dos queijos pelos julgadores não treinados foi realizada por meio do teste de aceitação sensorial descrito por Meilgaard et al. (1999). A análise sensorial do queijo foi feita em quatro períodos, com 30 provadores por período. As amostras foram codificadas e cortadas em cubos, com peso de $25 \mathrm{~g}$, e fornecidas em copinhos descartáveis. As amostras foram servidas simultaneamente e classificadas pelos provadores para avaliação da aceitação geral, dando-se a nota de valor 1 para a menos aceita e 9 para a mais aceita. Os dados foram avaliados calculando-se a diferença mínima significativa (DMS) da soma de ordens de cada amostra de acordo com o Método de Friedman, com nível de significância de 5 \% (Meilgaard et al., 1999).

Os dados relativos às características físico-químicas do leite e do queijo foram submetidos à análise de variância e, quando o teste de $\mathrm{F}$ foi significativo, as médias de tratamentos foram comparadas pelo teste de Scott-Knott, ao nível de 5\% de probabilidade, utilizando-se o programa estatístico SISVAR (Ferreira et al., 2011).

\section{Resultados e discussão}

Os valores de gordura e proteína do leite, assim como as demais variáveis da composição físico-química do leite, não foram influenciados $(P>0,05)$ pela substituição da silagem de sorgo pela casca de banana na dieta das vacas (Tabela 3 ). 
O percentual médio encontrado para a proteína foi $3,73 \%$, próximo ao reportado por Dormond et al. (1998), 3,48\% e 3,52\%, respectivamente, avaliando a inclusão de casca de banana em dois experimentos, utilizando vacas Jersey em lactação, inicial e intermediária. É importante ressaltar que o valor de proteína do leite encontrado está acima do mínimo de 2,9\% recomendado pela legislação vigente (Brasil, 2011).

A proteína do leite tem sido ao longo dos últimos anos, o nutriente de maior interesse para muitos pesquisadores, porque está diretamente relacionado com rendimento de derivados lácteos, o que pode aumentar a remuneração dos produtores. No entanto, a proteína do leite é um nutriente difícil de ser alterado. Apesar disso, uma dieta pobre em energia e proteína pode implicar diminuição dos teores de proteína láctea. Dietas com teores adequados de carboidratos fermentáveis no rúmen, utilização de forragem de boa qualidade, dietas com adequados teores de proteína não degradável no rúmen e fornecimento de aminoácidos essenciais como metionina e lisina contribuem para o aumento da porcentagem de proteína láctea (Ribeiro et al., 2014). Dessa forma, pode-se inferir que as dietas com a inclusão de casca de banana propiciaram um adequado aporte de energia e proteína para o rúmen e animal hospedeiro, assegurando uma adequada disponibilidade de proteína metabolizável, o que possibilitou os elevados teores de proteína no leite.

No presente estudo, deve-se ressaltar que a inclusão da casca de banana nas dietas em substituição à silagem de sorgo não influenciou os teores de gordura e proteína, mantendo, assim, a qualidade do mesmo. Com isso, fica evidente que a composição química da casca de banana é satisfatória para manutenção da qualidade do leite, visto que ela possui cerca de $8 \%$ de extrato etéreo, $8 \%$ de proteína bruta, carboidratos não fibrosos em torno de $13 \%$ (Tabela 2), que contribuem para o suprimento de energia para os microorganismos do rúmen que, juntamente com a proteína dietética, pode produzir adequada quantidade de proteína microbiana de alto valor biológico. Também em sua composição há grande quantidade de taninos variando de $3,5 \%$ a $40,5 \%$ (Clavijo, 1975) em casca mais maduras e verdes, respectivamente. Os taninos podem diminuir a degradabilidade da proteína no rúmen e aumentar o fluxo de aminoácidos essenciais para o intestino delgado de modo a contribuir positivamente para o suprimento desses e isso refletir na composição do leite. Assim, fica claro os benefícios que a casca de banana tem em sua composição química, e utilizá-la para alimentação animal não é só satisfatória do ponto de vista nutricional, como também um meio de aproveitamento desse subproduto que na maioria das vezes é descartado no ambiente sem nenhum tratamento, causando desequilíbrio ambiental.

O teor de lactose no leite também não diferiu entre as quatro dietas, o que era previsível, pois a lactose é o componente do leite que menos sofre alteração em decorrência da dieta, tendo em vista seu importante papel osmótico no leite (Reis, 2012). O teor médio encontrado $(4,93 \%)$ está nos limites esperados para leite de vacas.

Os teores dos sólidos totais não foram influenciados pelas dietas utilizadas $(P>0,05)$ (Tabela 3$)$. Verificou-se que o percentual médio de ST foi de $14,08 \%$, valor semelhante ao relatado $(14,11 \%)$ por Melo et al. (2017), em experimento avaliando a inclusão de cascas de banana em vacas de leite. Esse componente é um importante indicador da qualidade do leite, representado pela soma de todas as partes sólidas do leite consideradas, na indústria de lacticínios, como os componentes que promovem o rendimento em produtos oriundos do leite, e por meio dos quais se faz o pagamento ao produtor pelo produto entregue à indústria, principalmente gordura e proteína.

Os percentuais de cinzas e extrato seco desengordurado também não foram influenciados $(P>0,05)$ pela inclusão de casca de banana na dieta das vacas, verificando-se valores médios de 0,79 e $9,42 \%$, respectivamente. O valor do ESD está acima do limite mínimo preconizado pela legislação, de 8,4\% (Brasil, 2011).

No presente estudo, a densidade e o índice crioscópico obtiveram valores dentro daqueles preconizados pela legislação (Brasil, 2011) sem diferença significativa $(P>0,05)$ (Tabela 5).

A composição físico-química do queijo Minas frescal não apresentou diferença $(P>0,05)$ para gordura, proteína, sólidos totais (ST), umidade, e resíduo mineral fixo (RMF), entre as dietas com ou sem inclusão de casca de banana (Tabela 4).

Tabela 4: Composição físico-química, rendimento bruto e rendimento ajustado para o teor de umidade do queijo Minas frescal produzido com leite de vacas F1 Holandês X Zebu alimentadas com ou sem inclusão de casca de banana na dieta, com respectivas médias e coeficiente de variação (CV)

\begin{tabular}{|c|c|c|c|c|c|c|}
\hline \multirow[b]{2}{*}{ Variáveis } & \multicolumn{6}{|c|}{ Dietas Experimentais } \\
\hline & $\mathrm{SS}^{5}$ & $\mathrm{SS}^{5}+$ Casca & $\begin{array}{c}\mathrm{SS}^{5}+\text { Casca c/ } \\
\text { calcário }\end{array}$ & $\begin{array}{c}\mathrm{SS}^{5}+\text { Casca cl } \\
\text { óxido cálcio }\end{array}$ & Média geral & CV (\%) \\
\hline Umidade (\%) & $59,68^{a}$ & $60,78^{a}$ & $60,63^{a}$ & $62,63^{a}$ & 60,93 & 5,62 \\
\hline${ }^{1}$ EST $(\%)$ & $40,32^{\mathrm{a}}$ & $39,22^{a}$ & $39,37^{a}$ & $37,37^{\mathrm{a}}$ & 39,07 & 8,77 \\
\hline Gordura (\% EST) & $39,06^{a}$ & $40,08^{a}$ & $38,93^{a}$ & $43,40^{\mathrm{a}}$ & 40,36 & 8,06 \\
\hline Proteína (\% EST) & $41,61^{a}$ & $42,45^{\mathrm{a}}$ & $42,39^{a}$ & $44,28^{a}$ & 42,68 & 6,62 \\
\hline${ }^{2} \mathrm{RMF}$ (\% EST) & $6,15^{\mathrm{a}}$ & $5,63^{a}$ & $6,81^{a}$ & $6,96^{a}$ & 6,39 & 14,12 \\
\hline${ }^{3} \mathrm{RB}(\mathrm{kg} / \mathrm{kg})$ & $4,68^{a}$ & $4,55^{\mathrm{a}}$ & $4,97^{a}$ & $4,88^{a}$ & 4,77 & 9,09 \\
\hline${ }^{4} \mathrm{RA}(\mathrm{kg} / \mathrm{kg})$ & $5,00^{b}$ & $5,00^{b}$ & $5,50^{\mathrm{a}}$ & $5,75^{\mathrm{a}}$ & 5,31 & 7,19 \\
\hline Ácido lático (\%) & $0,18^{a}$ & $0,17^{a}$ & $0,17^{a}$ & $0,16^{a}$ & 0,17 & 10,50 \\
\hline $\mathrm{pH}$ & $6,55^{a}$ & $6,48^{a}$ & $6,5^{\mathrm{a}}$ & $6,59^{a}$ & 6,55 & 2,15 \\
\hline Textura (Kg) & $0,21^{a}$ & $0,19^{a}$ & $0,18^{a}$ & $0,20^{a}$ & 0,20 & 6,61 \\
\hline Aw & $0,98^{a}$ & $0,99^{a}$ & $0,99^{a}$ & $0,99^{a}$ & 0,99 & 0,95 \\
\hline
\end{tabular}

Médias seguidas de letras distintas diferem entre si pelo teste de Scott-Knott a $5 \%$ de probabilidade. ${ }^{2}$ RMF. Resíduo mineral fixo, ${ }^{1} \mathrm{ST}$ : extrato seco total. ${ }^{3} \mathrm{RB}$ : rendimento bruto. ${ }^{4} \mathrm{RA}$ : rendimento ajustado. ${ }^{5}$ Silagem de Sorgo 
Os resultados, quanto à composição físico-química do queijo, estão de acordo com a legislação vigente (Brasil, 1996; Brasil, 2004) para o queijo Minas frescal, que deve apresentar umidade não inferior a 55\%, caracterizando-o como queijo de alta umidade. Os queijos em estudo tiveram teor médio de umidade $60,93 \%$ (Tabela 6), recebendo assim essa classificação.

O resultado obtido para o teor de extrato seco total (EST) foi em média 39,07\%, estando acima do encontrado por Melo et al. (2017), que registrou média de $35,53 \%$ de EST em queijos Minas frescal produzidos com leite de vacas alimentadas com dietas contendo casca de banana. Martins et al. (2012) constataram valor médio de $43 \%$ para o queijo Minas frescal, avaliando diferentes volumosos.

Quanto ao teor de proteína bruta (PB) do queijo, o valor médio encontrado foi de $42,68 \%$ na matéria seca, devido aos altos teores de PB do leite, com média de 3,73\%. De acordo com a legislação Brasil (2004), a concentração de proteína varia até $40 \%$, sendo que a proteína predominante é a caseína. Machado et al. (2004) trabalhando com queijo tipo Minas frescal, registraram valores semelhantes aos deste trabalho para percentuais de proteína.

O teor de gordura está diretamente relacionado com a palatabilidade do produto e com a maciez, podendo influenciar também na coloração. Conforme a legislação vigente (Brasil, 2004), que preconiza um valor de gordura para o queijo Minas frescal entre 25 e 44,9\% no extrato seco total classificando-o como semigordo, os valores encontrados neste estudo estão dentro do que é exigido pela legislação, com média de $40,40 \%$ no extrato seco total (Tabela 4). Valores próximos a esse foram encontrados por Martins et al. (2012) quando se utilizou a silagem de sorgo em dietas para vacas mestiças.

Para o resíduo mineral fixo (RMF), as dietas estudadas proporcionaram percentual médio de $6,39 \%$ no EST, enquanto que Alves et al. (2011) avaliou a composição centesimal do queijo Minas Frescal e obteve no EST resultado médio de 4,1\% para cinzas.

No que diz respeito ao rendimento ajustado, os tratamentos com casca de banana tratada com calcário e óxido de cálcio foram iguais entre si $(P>0,05)$, e inferiores em relação às dietas sem casca e com casca de banana sem aditivo, que não diferiram entre si $(P>0,05)$ (Tabela 3$)$.

Sabe-se da influência que a composição do leite tem para o rendimento do queijo. Teor de proteínas e de gorduras tem papel fundamental na definição do rendimento. Em relação ao teor de gordura, o efeito positivo no rendimento está relacionado com uma maior retenção de água no queijo devido à menor síntese durante a elaboração deste. Por outro lado, no conteúdo de proteína, considera-se, sobretudo, a caseína do leite, que é a fração coagulável pelo coalho e que ao formar uma rede (paracaseinato de cálcio) "aprisiona", em diferentes proporções, os demais elementos do leite, como gordura, lactose e sais minerais (Furtado, 2005).

Os resultados das análises físico-químicas do queijo apresentados na tabela não diferiram estatisticamente $(P>0,05)$ quanto à acidez titulável, ao $\mathrm{pH}$ e à atividade de água (Aw). Estes valores foram semelhantes, quanto ao $\mathrm{pH}(6,55)$, aos encontrados por Marques e Oliveira (2004), em queijo Minas frescal armazenado por um período de 30 dias. Quanto à acidez, Rosa (2004) apresentou resultado inferior $(0,28 \%)$ de acidez em ácido láctico. Silva et al. (2003) reportaram valores de $\mathrm{pH}$ de 6,2 a 5,0 em queijo Minas frescal. Em relação à atividade de água, obteve-se um resultado médio de 0,98 , confirmando a alta umidade do queijo (Tabela 4).

Não houve efeito das dietas sobre a textura do queijo Minas frescal (Tabela 4), indicando que o queijo produzido com o leite de vacas F1 Holandês $x$ Zebu alimentadas com dietas contendo ou não a casca de banana pode ser considerado macio.

No presente trabalho, para o teste de aceitação, pôde-se observar que as médias variaram de 6,58 a 6,92, com uma média geral de 6,78. De acordo com os valores observados, o produto não teve alterações sensoriais percebidas pelos provadores, mantendo-se próximo à escala 7 correspondente a "gostei moderadamente" (Tabela 5). Resultados da análise sensorial do queijo Minas frescal produzido vacas F1 Holandês X Zebu alimentadas com ou sem inclusão de casca de banana na dieta, com respectivas médias e coeficientes de variação (CV)

Dietas Experimentais

\begin{tabular}{cccccc} 
SS $^{2}$ & SS $^{2}+$ Casca & $\begin{array}{c}\mathrm{SS}^{2}+\text { Casca } \mathrm{Cl} \\
\text { calcário }\end{array}$ & $\begin{array}{c}\mathrm{SS}^{2}+\text { Casca cl } \\
\text { óxido de cálcio }\end{array}$ & Média & CV(\%) \\
\hline $6,83^{\mathrm{a}}$ & $6,58^{\mathrm{a}}$ & $6,92^{\mathrm{a}}$ & $6,79^{\mathrm{a}}$ & 6,78 & 10,40 \\
120 & 120 & 120 & 120 & &
\end{tabular}

Médias seguidas com mesma letra, na linha, não diferem entre si $(p>0,05)$ pelo teste de Scott-Knott. $\mathrm{N}^{1}=$ número de provadores, ${ }^{2}$ Silagem de Sorgo.

Esses resultados remetem a preferência do consumidor ao tipo de queijo consumido. Os resultados da análise sensorial se aproximam mais da nota 9 "gostei extremamente" do que da nota 1 "desgostei extremamente". Dessa maneira, os resultados são satisfatórios para o teste de aceitação geral do queijo Minas frescal.

Resultados deste trabalho corroboram aqueles encontrados por Alves et al. (2011), em queijo Minas frescal, utilizando culturas lácticas, com médias variando de 6,4 a 7,0, indicando que os provadores gostaram ligeiramente ou moderadamente do produto. Machado et al. (2004) analisando o queijo Minas artesanal na região do Serro, empregando a escala hedônica de aceitação de nove pontos, constataram médias de 6,03 , o que indica que os provadores também gostaram ligeiramente do produto. Pode-se observar que os trabalhos com queijo Minas frescal tem uma similaridade com relação à aceitação, considerando a preferência do consumidor por esse tipo de queijo.

Trabalhos que avaliam o aproveitamento da casca de banana em dietas de vacas leiteiras e que consigam explorar ainda mais o seu valor nutricional devem ser objetivos de pesquisas, a fim de se obter resultados cada vez mais consistentes para a produção animal.

Com os resultados desta pesquisa, pode-se concluir que a utilização de casca de banana seca ao sol sem aditivos químicos adicionados durante o processo de secagem, em substituição parcial à silagem de sorgo, na dieta de vacas F1 Holandês $x$ Zebu, com produção média de 16,84Kg de leite corrigido para 3,5 $\%$ de gordura dia $^{-1}$, pode ser uma alternativa viável para produção e processamento do leite, mantendo a qualidade do produto. 


\section{Agradecimentos}

À FAPEMIG, CNPq e CAPES, pelo auxílio com bolsas e ao INCT-Ciência Animal.

\section{Referências}

AGUIAR, A.C.R.; OLIVEIRA, C.L.; CALDEIRA, L.A.; ROCHA JÚNIOR, V.R.; OLIVEIRA,S.J.; SOARES,C.; SILVA, D.A; MENEZES, J.C.; BORGES, L.D.A. Consumo, produção e composição do leite e do queijo de vacas alimentadas com níveis crescentes de ureia. Revista Brasileira de Ciência Veterinária, v. 20, n. 1, p. 37-42, 2013.

ALVES, C.C.C.; GEMAL, N.D.H.; CORTEZ, M.A.S. FRANCO, R. MANO, S.B. Utilização de Lactobacillus acidophilus e de acidificação direta na fabricação de queijo de minas frescal. Arquivo Brasileiro de Medicina Veterinária e Zootecnia, v.63, n.6, p.1559-1566. 2011.

ANDREATTA, E.; FERNANDES, A.M.; SANTOS, M.V. MUSSARELLI, C. Quality of Minas frescal cheese prepared from milk with different somatic cell counts. Pesquisa Agropecuária Brasileira, v.44, p.320-326, 2009.

BOSA, R.; FATURI, C.; VASCONCELOS, H.G.R.; CARDOSO, A.M.; RAMOS, A.F.O. AZEVEDO, J.C. Consumo e digestibilidade aparente de dietas com diferentes níveis de inclusão de torta de coco para alimentação de ovinos. Acta Scientia-rum. Animal Sciences, vol. 34, n. 1, p. 57 62. 2012.

BRASIL. Ministério da Agricultura, Pecuária e Abastecimento. Regulamento técnico para fixação de identidade e qualidade de queijos. Portaria no 146 de 07 de março de 1996. Disponível em: https://www.defesa.agricultura.sp.gov.br/legislacoes/portariamapa-146-de-07-03-1996,669.html. Acesso em: 13 mar. 2018.

BRASIL. Ministério da Agricultura, Pecuária e Abastecimento. Regulamento técnico para fixação de identidade e qualidade de queijos. Instrução Normativa n $^{\circ}$ 4, de 01 de março de 2004. Brasília, 2004. Disponível em: <http://www.jusbrasil.com. br/diarios/481206/pg-5-secao-1-diario-oficial-da-uniao-doude-05-03-2004>.Acesso em: 17 out. 2014

BRASIL. Ministério da Agricultura, Pecuária e Abastecimento. Métodos analíticos oficiais físico-químicos para controle de leite e produtos lácteos. Instrução Normativa $n^{\circ} .22$ de 14 de dezembro de 2006. Diário Oficial da União, Brasília, DF, 2006. Disponível em: <http://www.agricultura.gov.br>. Acesso em: 17 out. 2014.

BRASIL. Ministério da Agricultura, Pecuária e Abastecimento. Métodos Analíticos Oficiais Físico-Químicos para Controle de leite e Produtos Lácteos. Instrução Normativa n 62 , de 29 de dezembro de 2011. Disponível em: <http://www.agricultura.gov. br>. Acesso em: 18 out. 2014.

CARVALHO, G.G.P.; PIRES, A.J.V.; VELOSO, C.M..; MAGALHÃES, A.F.; FREIRE, M.A.L.; SILVA, F.F.da.; SILVA, R.R.; CARVALHO, B.A.de. Valor nutritivo do bagaço de cana-de-açúcar amonizado com quatro doses de ureia. Pesquisa Agropecuaria Brasileira, v.41, p.125-132, 2006.

CARUSO, E.C. Variação do teor de carboidratos totais em queijos Minas frescal e Minas padrão. 1997. 95p. Dissertação (Mestrado em Ciência e Tecnologia de Alimentos). Escola Superior de Agricultura Luiz de Queiroz, Piracicaba, 1997.

CLAVIJO, H. MANER, J.H. The use of waste bananas for swine feed. CONFERENCE ON ANIMALS FEEDS OF TROPICAL AND SUBTROPICAL ORIGIN, 1975, London. Proceedings. London: Tropical Products Institute, 1975. p. 99-106.
DEMEYER, D.; DOREAU, M. Targets and procedures for altering ruminant meat and milk lipids. Proceedings of the Nutrition Society.London, v. 58, p. 593-607, 1999.

DORMOND, H. ; BOSHINI, C. ; ROJAS-BOURRIILÓN, A. Efecto de dos niveles de cascara de banano maduro sobre la produccion lactea en ganado lechero. Agrononúa Costarricense 22(1): 43-49. 1998.

FERNANDES, M.F.; QUEIROGA, R.C.R.E.; MEDEIROS, A.N.; COSTA, R.G.; BOMFIM, MA.D.; BRAGA, A.A. Características físico-químicas e perfil lipídico do leite de cabras mestiças Moxotó alimentadas com dietas suplementadas com óleo de semente de algodão ou de girassol. Revista Brasileira de Zootecnia, v.37, p.703-710, 2008.

FERREIRA, D.F. SISVAR: A computer statistical analysis system. Ciência e Agrotecnologia, v. 35, n. 6, p. 1039-1042, 2011.

FURTADO, M.M. Principais problemas dos queijos: Causas e Prevenção. São Paulo: Fonte Comunicações e Editora, 2005. $200 \mathrm{p}$.

FURTADO, M.M.; LOURENÇO NETO, J. P. M. Tecnologia de queijos: manual técnico para produção industrial de queijos. 1.ed. São Paulo: Dipemar, 1994. 118 p.

HAVSTEEN, B.H. The biochemistry and medical significance of the flavonoids. Pharmacology \& Therapeutics, [s.I.], v. 96, n. 2, p. 67-202, 2002.

HARRIS Jr., B.; BACHAMAN, K. C. Nutritional and management factors affecting solid-non-fat, acidity and freezing point of milk. Gainesville: Institute of Food and Agricultural Sciences, 1988.

LOUSADA JÚNIOR, J.E.; NEIVA, J.N.; RODRIGUEZ, N.M.; PIMENTEL, J.C.M.; LÔBO, R. N.B.; Consumo e digestibilidade aparente de subprodutos do processamento de frutas em ovinos. Revista Brasileira de Zootecnia, v.34, n.2, p.659-669, 2005.

LUCEY, J.; KELLY, J. Cheese yield. Journal of the Society of Dairy Technology, Champaign, v. 47, n. 1, p.1-14, 1994.

MACHADO, E.C.; FERREIRA, C.L.L.F.; FONSECA, L.M.; SOARES, F.M; PEREIRA JÚNIOR, F.N.; Características físicoquímicas e sensoriais do queijo minas frescal artesanal produzido na região do Serro, Minas Gerais. Departamento de Tecnologia de Alimentos - UFV. Departamento de Tecnologia e inspeção de Produtos de Origem Animal - UFMG, 2004.

MAHOPATRA, D.; MISHRA, S.; SUTAR, N.; Banana and its byproduct utilisation: an overview. Journal of Scientific \& Industrial Research, [s.I.], v. 69, p. 323-329, 2010.

MARQUES, M. C.; OLIVEIRA, C. A. F. Avaliação das características físico-químicas do queijo Minas frescal produzido com leite contendo diferentes níveis de células somáticas. Pirassununga: FZEA/USP, 2004. 15 p.

MARTINS, S.C.S.G.; ROCHA JR, V.R.;CALDEIRA, L.A.; REIS, S.T.; BARROS, I.C.; OLIVEIRA, J.A. Rendimento, composição e análise sensorial do queijo minas frescal fabricado com leite de vacas mestiças alimentadas com diferentes volumosos. Revista Brasileira de Zootecnia, v. 41, n.4, p.994, 2012.

MEILGAARD, M.; CIVILLE, G. V.; CARR, B. T. Sensory evaluation techniques. Boca Raton: CRC Press, 1999. v. 2. 387 p. 
MELO, M.T.P.; ROCHA JÚNIOR, V.R.; CALDEIRA, L.A.; PIMENTEL, P.R.S.; REIS, S.T.; JESUS, D.L.S. Cheese and milk quality of F1 Holstein $x$ Zebu cows fed different levels of banana peel. Acta Scientiarum. Animal Sciences, v.32, n.2, p.181-187, 2017.

NATIONAL RESEARCH COUNCIL - NRC. Nutrient requirements of dairy cattle. 7. ed. Washington, D.C.: National Academy Press, 2001. $381 \mathrm{p}$

NUDDA, A.; BATTACONE, G.; BOAVENTURA NETO, O.; CANNAS, A.; FRACESCONI, A.H.D.; ATIZORI, A.S.; PULINA, G. Feeding strategies to design the fatty acid profile of sheep milk and cheese. Revista Brasileira Zootecnia, v.43, n.8, p. 445-456, 2014

OLIVEIRA, M.A.; REIS, R.B.; LADEIRA, M.M.; PEREIRA, I.G.; FRANCO, G.L.; SATURNINO, H.M.; COELHO,

S.G.;ARTUNDUAGA, M.A.T.; FARIA, B.N.; SOUZA JÚNIOR, J.A. Produção e composição do leite de vacas alimentadas com dietas com diferentes proporções de forragem e teores de lipídeos. Arquivo Brasileiro de Medicina Veterinária e Zootecnia, v.59, p.759-766, 2007.

OMER, S. In situ dry matter degradation cha-racteristics of banana rejects,leaves, and pseudo stem. Assiut Veterinary Medicine Journal. [s.I.], v. 55, n. 1, p. 120-129, 2009.

PIMENTEL, P.R.S.; ROCHA JÚNIOR, V.R.; MELO, M.T.P.; RUAS, J.R.M.; BRANT, L.M.S.; COSTA, N.M.; LEITE, G.D.O.; LEITE, M.D.O.; MARANHÃO, C.M.A. Banana peel in the diet for F1 Holstein x Zebu cows. Semina: Ciências Agrárias, v.38, n.2, p.969-980, 2017

REIS, A.M.; COSTA, M.R.; COSTA, R.G.; SUGUIMOTO, H.H.; SOUZA, C.H.B.; ARAGON-ALEGRO, L.C.; SANTANA, E.H.W. Efeito do grupo racial e do número de lactações sobre a produtividade e a composição do leite bovino. Semina: Ciências Agrárias, v.33, n.2, p.3421-3436, 2012.
RIBEIRO, C.G.S.; LOPES, F.C.F.; GAMA, M.A.S.; MORENZ, M.J.F.; RODRIGUEZ, N.M. Desempenho produtivo e perfil de ácidos graxos do leite de vacas que receberam níveis crescentes de oleo de girassol em dietas à base de capim-elefante. Arquivo Brasileiro de Medicina Veterinária e Zootecnia, v.66, n.5, p.15131521, 2014.

ROSA, V.P. Efeitos da atmosfera modificada e da irradiação sobre as características microbiológicas, físico-químicas e sensoriais do queijo Minas Frescal. 2004. 141f. Dissertação (Mestrado em Ciência e Tecnologia de Alimentos) - Escola Superior de Agricultura Luiz de Queiroz, Universidade de São Paulo. 2004.

SILVA, I. M.M. et al. Occurrence of Listeria SSP in critical control points and the environment of Minas frescal cheese processing. International Journal of Food Microbiology, Amsderdam, v. 81, p. 241-248, 2003

SIMILI, F.F.; LIMA, M. L. P.; Como os alimentos podem afetar a composição do leite das vacas. Pesquisa \& Tecnologia, São Paulo, v. 4, n.1, Jan-Jun 2007.

SKLAN, D. R. et al. Fatty acids, calcium soaps of fatty acids, and cottonseeds fed to high yielding cows. Journal of Dairy Science, Champaign, v. 75, n. 9, p. 2463-2472, 1994.

TORAL, P, G.; HERVÁZ, G.; BICHI, H.; BELENGUER, A.; FRUTOS, P.; Tannins as feed additives to modulate ruminal biohydrogenation: Effects on animal performance, milk fatty acid composition and ruminal fermentation in dairy ewes fed a diet containing sunflower oil. Animal Feed Science and Technology, Amsterdam, v. 164, p. 199-206, 2011. 